\title{
ESPACIO PÚBLICO Y NUEVAS CENTRALIDADES URBANAS EN MÉXICO La concepción socio-espacial del Centro Cívico de Querétaro
}

\author{
PUBLIC SPACE AND NEW URBAN CENTRALITIES IN MEXICO \\ The socio-spatial production of the Civic Center of Querétaro \\ Morales Pozo, Luis Vladimir \\ (Doctorado en Urbanismo, Universidad Nacional Autónoma de México) arqritica.ec@gmail.com
}

\section{RESUMEN}

La ponencia plantea destacar la importancia que representa, en la problemática del espacio público contemporáneo, la concepción de nuevas centralidades producidas en México y en especial las denominadas como centros cívicos. Se realizan primeramente dos aproximaciones: una teórica referente a la producción de nuevas centralidades y su relación con el espacio público; y otra, histórica-conceptual sobre la concepción de la categoría que en planificación urbana se denomina centro cívico, en el contexto de la planificación estratégica. Luego se analiza la concepción del caso de estudio en Querétaro.

Palabras clave: espacio público, centralidad, producción socio-espacial, Querétaro.

Bloque temático: espacio público y proyecto urbano en la metrópolis contemporánea.

\begin{abstract}
The paper proposes to highlight the importance that the conception of new centralities produced in Mexico and especially those designated as civic centers represents in the problematic of contemporary public space. First two approaches are carried out: a theoretical one referring to the production of new centralities and their relationship with the public space; and another, historical-conceptual on the conception of the category that in urban planning is called civic center, in the context of strategic planning. Then the conception of the case study in Querétaro is analyzed.
\end{abstract}

Keywords: public space, centrality, socio-spatial production, Querétaro Topic: public space and urban project in the contemporary metropolis 


\section{Introducción}

La reubicación de la administración pública local en periferias urbanas se ha constituido en una práctica recurrente que busca alcanzar la eficiencia administrativa y funcional del Estado en el siglo XXI. En cada vez más ciudades latinoamericanas se relocalizan y concentran funciones gubernamentales en nuevos objetos urbano-arquitectónicos concebidos como nuevas centralidades urbanas y se construyen discursos oficiales e imaginarios colectivos sobre ellas. Estas centralidades han sido concebidas también, como nuevos centros cívicos y presentan al espacio público como elemento esencial de una concepción que transforma la realidad urbana en base a planeaciones estratégicas, gestiones público-privadas y políticas urbanas similares.

Esta concepción, de centros cívicos y espacios públicos, se tematiza inmersa en la teoría de la producción social del espacio (Lefebvre, [1974] 2013) que plantea que la concepción (planeación), así como la vivencia y percepción, son formas de transformar tanto a las ciudades como a lo urbano. Así, la presente ponencia se basa en esta teoría unitaria del espacio que desarrolla además una tríada conceptual para explicar, por un lado, las representaciones de las relaciones de producción y de poder desarrolladas en el espacio; y por otro, cómo el espacio representa esas relaciones en sus edificios. La tríada se compone por la práctica espacial, las representaciones del espacio y los espacios de representación; términos espaciales a los que les corresponden respectivamente tres momentos del espacio social: espacio percibido, espacio concebido y espacio vivido.

La práctica espacial de una sociedad se descubre al descifrar su espacio: el espacio percibido asocia la realidad cotidiana y la realidad urbana; concierne al espacio social y a la relación con el espacio de cada individuo de una sociedad determinada; y, permite conocer la transformación urbana histórica de una ciudad y por ende sus prácticas sociales. Las representaciones del espacio se vinculan a los conocimientos, signos, códigos y relaciones presentes en la concepción del espacio: es el espacio concebido por los urbanistas, tecnócratas, artistas y políticos; se refiere a la conceptualización de la ciudad y permite entender la ideología dominante en la producción social del espacio. Los espacios de representación expresan simbolismos e imágenes ligadas a la vida social y corresponden al espacio vivido por la población de la ciudad.

Esta teoría evidencia también que en la época contemporánea se produce un espacio abstracto dominante que es manipulado e instrumentalizado por el poder, es decir, un espacio concebido de forma cuantificable y formal para negar las diferencias y homogenizar la ciudad, en pro de adecuarla a las exigencias de los poderes dominantes políticos o económicos. Pero este espacio abstracto presenta contradicciones al no considerar prácticas sociales que producen un espacio diferencial y en el que se desarrollan diferentes lógicas de usos y de apropiaciones sociales para conquistar aquel espacio concebido por las esferas de poder. En esta teoría se plantea justamente el análisis de las centralidades urbanas como espacios que develan estas tensiones.

\section{Nuevas centralidades urbanas y espacio público}

La centralidad urbana se refiere a un polo de atracción generado por la concentración y accesibilidad de funciones urbanas, colectivas y simbólicas, como el encuentro social y las actividades civiles, comerciales, culturales o de gobierno (Delgadillo, 2017). Se entiende también como una relación, por lo que es difícil delimitarla en base a un tiempo determinado o a funciones centrales específicas (Carrión, 2017). También es el espacio que posiblemente permita aproximarse más objetivamente a la problemática espacial de las ciudades, al referirse tanto al espacio social como al mental y sobrepasar así la separación entre objeto y sujeto (Lefebvre, ([1974] 2013). Por último, debido a que contiene las mayores escala, funcionalidad, población y conflictividad; ha sido considerada como el más importante espacio público de la ciudad (Carrión, 2016).

Históricamente, el crecimiento urbano en México se ha estructurado en base a: 1) poblados rurales (prehispánicos o extensiones de asentamientos coloniales); 2) traza en damero y centralidad política y religiosa en la colonia; y 3) espacio público, jerarquización de vías (caracterizadoras de las edificaciones) y centralidades 
definidas por corredores comerciales, parques y plazas a partir del siglo XIX (Duhau y Giglia, 2008). Estas centralidades generadas se han ido consolidando en el siglo $X X$ toda vez que, en relación con las actividades económicas y la estructura urbana, existe una reconcentración de actividades terciarias producida por la desindustrialización y la transformación del sector del comercio y los servicios (Duhau y Giglia; 2004).

En este sentido, desde la segunda mitad del siglo pasado, existen modalidades de urbanización que han operado como dispositivos del proceso de expansión urbana, por la incorporación de nuevas áreas al desarrollo urbano, y que se producen por 1) fraccionamientos habitacionales, como suburbios residenciales dependientes funcionalmente de la ciudad central y destinados a todos los estratos sociales; 2) vivienda de interés social, en muchos casos producida masivamente; 3) barrios populares no regulados y 4) conjuntos urbanos que integran residencia, comercio y servicios (Duhau y Giglia, 2008). Estos conjuntos urbanos son los que a partir de finales del siglo pasado se han producido como nuevas centralidades urbanas.

La nueva forma urbana de la ciudad latinoamericana (De Mattos, 2010) se describe como una trama continua de asentamientos, organizada alrededor de focos nodales especializados en una vasta región multicentrada; es decir, espacio urbano organizado alrededor de fragmentos dispuestos por la explosión del centro de la ciudad. En este escenario, las nuevas centralidades cobran relevancia en la organización y el funcionamiento de la forma urbana, toda vez que, la economía mundializada no solo se refiere a flujos sino también a polos territoriales. Estas centralidades albergan expresiones urbano-arquitectónicas que tienen funciones comerciales y de servicios de salud, educación, cultura, esparcimiento, religión, administración pública y privada, entre otros. La diferencia de estas nuevas centralidades y las tradicionales históricas radica en el aumento de su complejidad, producto de una diversificación del consumo y de servicios que se caracterizan por contar con la presencia de nuevos objetos urbano-arquitectónicos cuya concepción asume al espacio público como elemento esencial e ideologizado (Delgado, 2011).

Estos nuevos espacios urbanos, producidos por lo que se ha denominado urbanismo insular (Duhau y Giglia, 2008), se han convertido en modalidades dominantes de la expansión regulada y la renovación del espacio urbano; y se presentan como elementos de ruptura con las formas precedentes del espacio urbanizado. Este proceso de producción y organización del espacio urbano hace énfasis en la ciudad como escenario y como conjunto de proyectos diferenciados que separan funciones y grupos sociales. Este funcionalismo, que se diferencia del pregonado por el racionalismo, no se interesa por un plan maestro conjunto de ciudad, sino que desarrolla tres procesos concurrentes: minimización del modelo público de ciudad junto con el poder estatal regulador, implantación de espacios comerciales en nodos viales sin que sean necesarias áreas habitacionales; y, conectividad y movilidad a través del automóvil.

Es decir, la ciudad latinoamericana contemporánea presenta un tejido urbano compuesto por fragmentos metropolitanos que son interdependientes entre sí y configuran un orden urbano con una aparente oposición entre fragmentación e interdependencia, tanto a nivel cultural, social y espacial (Duhau y Giglia, 2016). Las relaciones de interdependencia entre los fragmentos urbanos ocurren en una base material constituida sobre todo en el espacio público de las ciudades que, al ser el lugar con mayor densidad de infraestructuras, viabiliza el funcionamiento y la especificad de la ciudad tanto por su condición urbana como por su cualidad histórica. Esta situación conlleva a que el espacio público tenga diversos significados o dimensiones, entre ellas el de espacio urbano, y amplía su concepto a la "cosa pública" o la política (Delgadillo, 2014).

El espacio público es definido por tres criterios (Rabotnikof, 2005): a) es de interés o de utilidad común y representa a lo colectivo; b) es visible, manifiesto y ostensible; y c) es accesible para toda la población porque es abierto. Estos sentidos básicos del espacio público se desarrollan en el par público-privado, considerado como categoría política, y se han articulado históricamente de forma diferente para producir modificaciones en el significado de lo público. Es en la época contemporánea que el espacio público se idealiza y se pone al servicio de la reapropiación capitalista de las ciudades al ser el elemento inmanente de la morfología urbana, estar abierto legalmente a la población y organizar el vínculo social y de relación con el poder (Delgado, 2011). 
Es también con el capitalismo neoliberal y los fenómenos de privatización, segregación, deterioro o desaparición del espacio público, que se hace necesario considerar las transformaciones normativas, funcionales, morfológicas y las representaciones simbólicas para abordar estas problemáticas en la producción del espacio público (Duhau y Giglia, 2016); sobretodo en su relación con las formas de organización del espacio urbano. Estas formas pueden ser barrios o unidades equivalentes, equipamientos públicos, nodos de circulación y transporte; y, espacios centrales: históricos y nuevas centralidades secundarias, como los centros cívicos.

\section{Centro cívico, proyecto urbano y planificación estratégica}

Si el orden urbano permite pensar la unidad de los fragmentos urbanos (Duhau y Giglia, 2016), es necesario considerar que la fragmentación urbana se da en la actualidad como una nueva forma de segregación urbana, después de la ocasionada por los espacios mono funcionales y la zonificación del urbanismo funcionalista (Carrión, 2016). Cabe señalar que la zonificación, entendida como la segregación espacial de actividades urbanas y surgida en el planeamiento de la ciudad industrial de finales del siglo XIX, fue reintroducida por el Movimiento Moderno como un instrumento de abstracción para entronizar un nuevo paradigma urbanístico: un modelo de ciudad basado en principios de segregación de usos de suelo, de jerarquía en las redes de servicios y de racionalización de los edificios sobre la tipología de un bloque aislado que rompería con la manzana cerrada, propia de la ciudad compacta (Herce, 2013).

Con esta segregación socio-espacial surgieron los llamados centros cívicos, cuya denominación aparece precisamente en el Congreso Internacional de Arquitectura Moderna (CIAM) de 1933 y en el que se elaboró la Carta de Urbanismo condensada por Le Corbusier en 1942 bajo el nombre de Carta de Atenas. En esta Carta se planteó una zonificación clasificada por usos de vivienda, de producción, de aislamiento, de centro cívico, de centro administrativo y de expansión cultural; es decir una radical segregación de usos que terminó por romper la ciudad, física y socialmente. El centro cívico fue concebido como un nuevo tipo de espacio urbano que permitía el encuentro de la ciudadanía en una zona peatonal que concentraba actividades como: universidades, museos, salas de conciertos, teatros, estudios y monumentos; éstos últimos para responder a los nuevos requisitos representativos y referenciales de la vida emocional de la comunidad. Es decir, centro cívico y monumentalidad serían la proyección de equipamientos para el espíritu comunitario con el supuesto de que la forma física determinaría el comportamiento de la gente: la arquitectura y el urbanismo moldearían su manera de actuar (García, 2016).

En esta época se elaboró lo que se consideraba como un procedimiento idóneo para construir una nueva estructuración de la comunidad humana a través de la gestión pública: la planificación. Esta reciente disciplina fue adoptada de forma dominante por una concepción que preconizaba la mayor intervención del Estado en dos vertientes: una marxista que planificaba la sociedad socialista y una capitalista que planificaba el desarrollo del capital. Ambas establecieron distintas orientaciones y propósitos tanto en la gestión como en las políticas púbicas (De Mattos, 2010). Pero en la práctica el urbanismo funcionalista fracasó con tres órdenes de efectos negativos: el morfológico, que fragmentaba el tejido urbano; el sociológico, que segregaba a los grupos sociales; y el ideológico, que no reconocía diferentes lógicas locacionales (García, 2016). La planificación en este urbanismo normativo se constituyó entonces en un racionalismo simplificador y descontextualizado que no reconocía a los condicionamientos sociales estructurales y mostró su incapacidad para enfrentar los problemas socio-económicos tanto de países socialistas como capitalistas (De Mattos, 2010). Así, esta concepción urbanística de planes directores se limitó a modelar las ciudades en base a un urbanismo y una gestión pública que trataban a la ciudad como un gran objeto arquitectónico.

En este marco de contradicciones existentes entre los grandes proyectos arquitectónicos y los planes urbanos en la década de los setentas del siglo pasado, aparece la noción de proyecto urbano para definir a una acción pública sobre un lugar específico de la ciudad, pero articulada a una visión total de la misma, así como a sus 
problemas socio-económicos (Lungo, 2005). Este proyecto urbano, definía justamente un conjunto de proyectos tendentes a la consecución de un modelo de ciudad heredado del urbanismo funcionalista e integrando las condiciones morfológicas del entorno con las condiciones a crear sobre él (Herce, 2013). Son estos proyectos urbanos los que desencadenarán la emergencia de múltiples centralidades cuando, siguiendo los parámetros de ordenamiento y recentralización del urbanismo racional normativo, las funciones administrativas fueron desplazadas fuera de la centralidad histórica, aunque ésta seguía conservando algunos de sus elementos básicos y simbólicos como ciertos edificios de gobierno, educativos, iglesias, bancos y comercio (Delgadillo, 2011).

A finales del siglo XX, sobre todo en el urbanismo europeo, aparecen así los grandes proyectos urbanos para articular estrategias urbanas y socio-económicas que cuestionaban a la planificación tradicional y se generan en una planificación estratégica: ser motores de la transformación urbana; romper los límites de los planes directores; incorporar al sector privado en la gestión, aunque la obra sea pública; o tener orígenes diversos, pero contar con actores urbanos relevantes, incluida una muy importante participación ciudadana. Sin embargo, muchos de estos grandes proyectos urbanos han ocasionado también segregación urbana e impactos ambientales negativos y han creado condiciones para, por iniciativa gubernamental, canalizar al sector privado los beneficios de la recuperación de su entorno inmediato (Lungo, 2005).

En Latinoamérica, en el siglo XXI, se han adoptado estos proyectos urbanos en base a planificaciones estratégicas que han retomado la concepción de centros cívicos propuesta por el urbanismo funcionalista para relocalizar y concentrar la administración pública gubernamental. En el caso de México se han producido así la Torre Ciudadana del Gobierno del Estado de Nuevo León en Monterrey (2010), la Ciudad Administrativa del Estado de Zacatecas (2012), el nuevo Edificio de Gobierno del Estado de Chihahua (2014) y el Centro de Gobierno del Estado de Guanuajato (2017). Como estudio de caso en este artículo se presenta la concepción del Centro Cívico de Querétaro, construido en 2003, por ser justamente uno de los primeros producidos en México en el siglo XXI.

\section{La concepción del Centro Cívico de Querétaro}

Para abordar la concepción del Centro Cívico de Querétaro, inaugurado en el año 2003 y ubicado en el Centro Sur, Delegación Josefa Vergara y Hernández de la ciudad de Querétaro (Duering, 2015); es necesario, enmarcados en el paradigma lefebvriano de que no hay espacio sin relaciones sociales ni relaciones sociales sin espacio, recurrir a una reconstrucción histórica de la planificación urbana en esta ciudad y que pertenece al Estado del mismo nombre en la República Mexicana. Así, la planeación urbana inició con la promulgación en 1976 de la Ley para el Desarrollo Urbano del Estado de Querétaro (Sombra de Arteaga, 21 de octubre de 1976), que tuvo como objeto ordenar la planeación, fundación, conservación, mejoramiento y crecimiento de los centros de población del estado, sobre todo de la ciudad de Querétaro, que tendrá un crecimiento acelerado de población: de 112.000 hab. en 1970 a 626.000 hab. en 2010. Este crecimiento será el que desde los años noventa del siglo pasado permita la conformación de la Zona Metropolitana de Querétaro (Ver Fig. 01).

Esta Ley pretendía mejorar las condiciones de vida de la población (urbana y rural) a través del aprovechamiento de los recursos naturales en beneficio social, la distribución equilibrada de la población en el territorio, el fomento de una adecuada interrelación socioeconómica del estado con toda la nación, una eficiente interacción y convivencia entre los sistemas y servicios de los centros de población, una relación adecuada entre la industria y la vivienda, la promoción y orientación de una mayor participación ciudadana, la regulación del mercado del suelo; y, la promoción de obras necesarias para dotar de vivienda digna a toda la población. La ley también perseguía promover acciones tendientes a la integración social y sugería la elaboración de planes parciales que solventen las necesidades de las comunidades. 


\section{SIIU}

barcelona|santiago de chile junio 2019
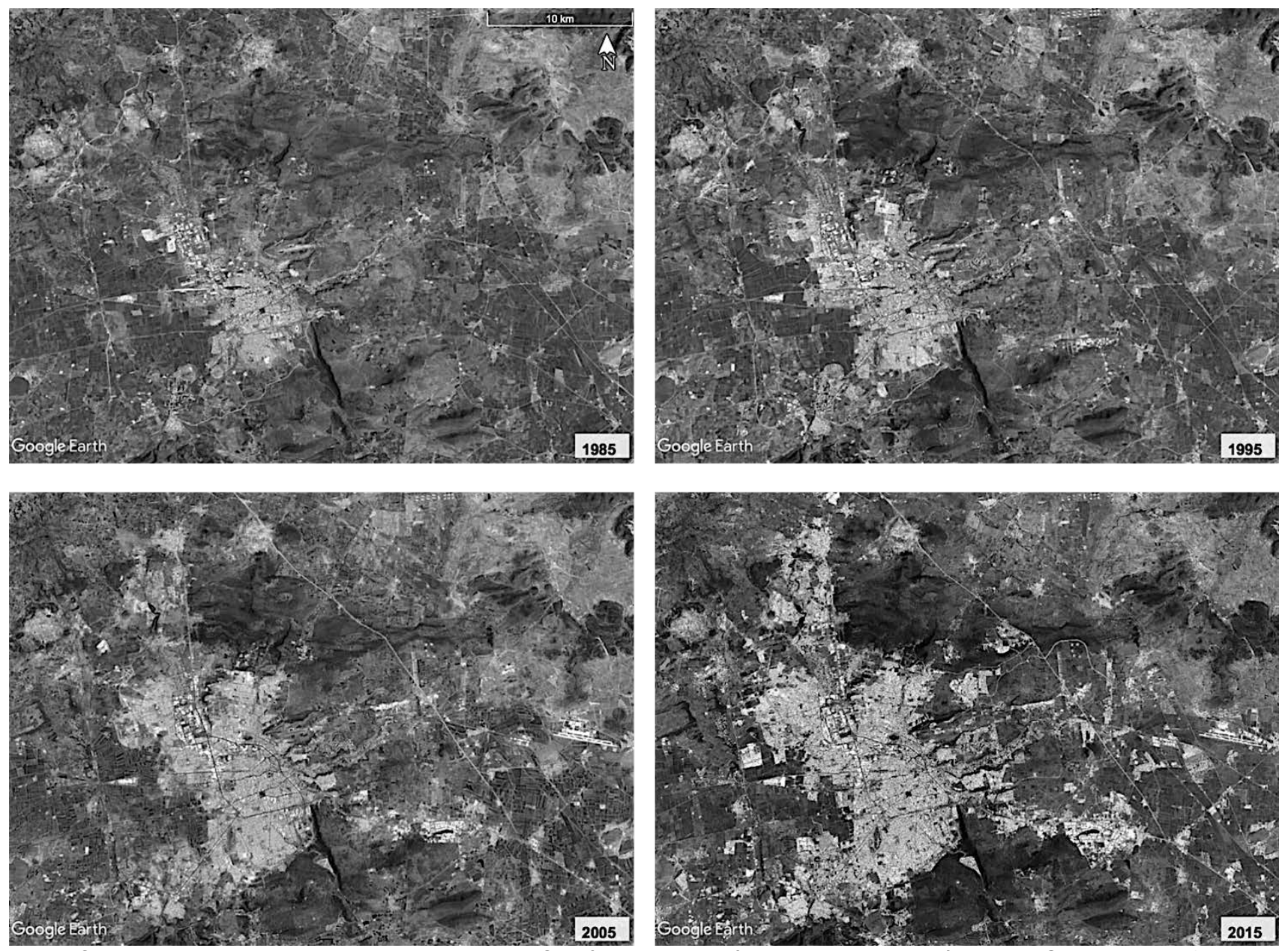

Fig. 01 Crecimiento de la Mancha Urbana de la ciudad de Querétaro. Elaboración propia a partir de imágenes de Google Earth, años 1985, 1995, 2005 y 2015.

El Congreso del Estado de Querétaro aprueba en 1979 el Plan Estatal de Desarrollo Urbano como primer instrumento jurídico - técnico para implementar en la entidad. Este Plan será actualizado en primera instancia en 1995 para luego ser estructurado como Plan Estatal de Desarrollo 1998-2003 (Sombra de Arteaga, 10 de abril de 1998), toda vez que la Zona Metropolitana de Querétaro tuvo un incremento acelerado (3,5\% anual) de población entre 1990 (560 mil hab.) y 2000 (816 mil hab.). En el año 2010 (un millón cien mil hab.) la población prácticamente duplicaría la de 1990. Esta última estructura contemplaba cuatro niveles. El primero se refería a los grandes ejes de acción para organizar congruentemente la gestión gubernamental. El segundo nivel planteaba los lineamientos de: fortalecimiento jurídico; seguridad y justicia; participación social y cultura; política y reforma del estado; fortalecimiento económico; planeación urbana e infraestructura; desarrollo humano e integral; $y$, mejoramiento de la administración gubernamental. El tercero presentaba los proyectos estratégicos derivados de los lineamientos expuestos y mediante los cuales se concretaba la obra gubernamental y se derivaban los programas a las respectivas dependencias. El cuarto nivel integraba los principales compromisos del gobierno del estado, como los correspondientes al agua y la vivienda.

Después de formulado el primer Plan Estatal de Desarrollo Urbano en 1979, se hizo necesario elaborar planes municipales de desarrollo urbano para cada uno de los municipios de la entidad. Así, en 1980 se elaboró el Plan Municipal de Desarrollo Urbano para el Municipio de Querétaro (Sombra de Arteaga, 27 de noviembre de 1980); y se plasmó la idea de racionalizar la distribución en el territorio municipal de la población y las actividades económicas para propiciar condiciones que permitan a la población acceder a vivienda, servicios públicos, infraestructura y equipamiento urbano. Se crean también, de forma estratégica, programas de acción 
concentrada como el de Asentamientos Humanos, que contemplaba la planeación del suelo y equipamientos urbanos. Este Plan se actualizaría en 1983.

Luego, en 1982 se elabora el Plan de Desarrollo Urbano de Centro de Población de la Ciudad de Querétaro (Sombra de Arteaga, 13 de enero de 1983). En este Plan Director Urbano, se presentaron los problemas relativos a los asentamientos desordenados, por lo que se planteó frenar el crecimiento de la ciudad hacia el poniente y proteger los mantos acuíferos y el Centro Histórico; es decir, orientar este crecimiento en el sentido norte - sur y no en el este - oeste, para no afectar tierras fértiles del Bajío o construir parte de la ciudad en el estado de Guanajuato. En este Plan se estructura la ciudad en base a varios sub-centros de apoyo: Norte, Sur y centro urbano; además de plantear un parque urbano (Ver Fig. 02). Este modelo bipolar se basa en un desarrollo que controlaba el crecimiento y protegía a la ciudad. Así, la estructura urbana planteada aquí para el año 2000 se refería a un centro de la ciudad y tres sub-centros urbanos localizados: al norte en MenchacaPeñuelas (no construido), al sur en las faldas del Cimatario (dónde se ubicará luego el Centro Cívico) y un tercero integrado al centro urbano actual (que potenciaría el centro histórico). Las zonas industriales se ubicarían al norte y oriente de la ciudad. Este Plan será actualizado en 1987 y 1994 (se explicará más adelante).

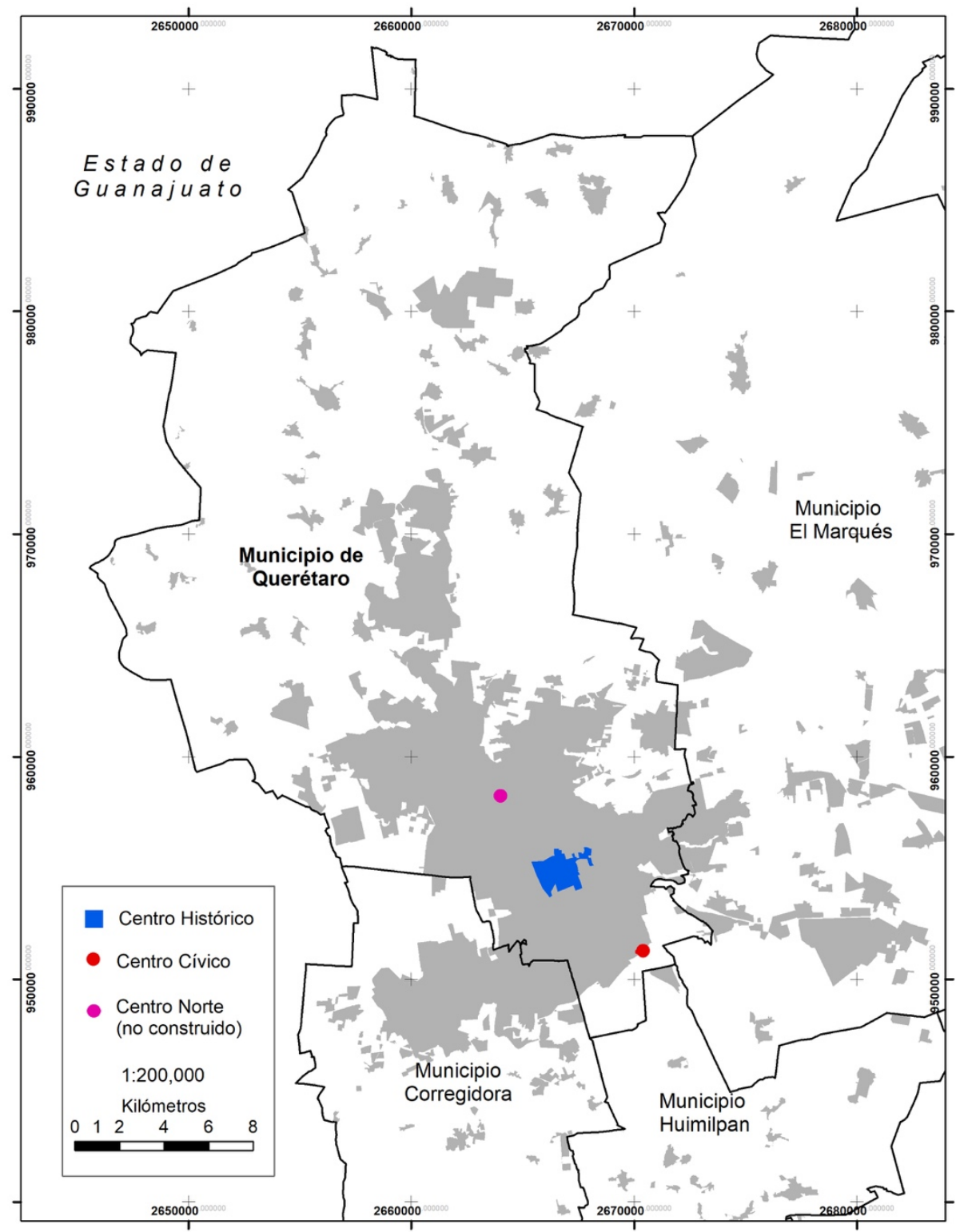

Fig. 02 Centros de la ciudad de Querétaro. Elaboración propia. 
A partir del reconocimiento del fenómeno de conurbación entre los municipios de Querétaro, Corregidora, El Marqués, y Huimilpan (Ver Fig. 02), en 1991 se declara el Programa de Ordenación de la Zona Conurbada de la Ciudad de Querétaro (Sombra de Arteaga, 19 de septiembre de 1991). Este programa buscaba dar mayor coherencia a las acciones que desarrollaban estos municipios para integrarlos, coordinarlos y resolver los problemas de ocupación de suelo agrícola de alta productividad por los usos urbanos. Pretendía además controlar el crecimiento urbano extensivo y desarticulado de las áreas urbanas consolidadas; así como el desequilibrio en la dotación de servicios y equipamiento urbano y de ocupación de áreas de valor ecológico.

En 1994, cuando se actualiza el Plan de Desarrollo Urbano de Centro de Población de la Ciudad de Querétaro (Sombra de Arteaga, 05 de mayo de 1994), se plantea que existe la excesiva concentración de actividades administrativas, educativas y comerciales en el Centro Histórico, por lo que se prevé adquirir tierras para atender las demandas futuras, así como construir infraestructura, equipamiento y servicios. Se muestra la necesidad de regularizar ciertos asentamientos, así como frenar la expansión de otros, y favorecer el crecimiento territorial hacia las zonas norte, sureste y sur. En el afán de consolidar un módulo de centros urbanos, sub-centros y centros de barrio, se genera un acuerdo para otorgar facilidades administrativas a proyectos de desarrollo urbano que se ubiquen en esos lugares (como el Centro Sur, en el que se construirá después el Centro Cívico). Precisamente se reconoce que el Centro Sur será un nuevo espacio de desarrollo urbano planificado y ordenado, que satisfaga las demandas de habitación, comercio y servicios públicos y privados que el crecimiento de la ciudad requiere en los próximos años, apoyando así a la conservación del Centro Histórico.

En este mismo año de 1994 se crea un Programa de Coordinación Administrativa de las acciones que desarrollen los fideicomisos en los que el estado participe; que se denomina Fideicomiso Promotor de Proyectos Económicos y de Bienestar Social "QroNos" y que será el que coordine la construcción del Centro Sur de la ciudad dónde se ubicará al Centro Cívico. También se aprueba en este año el Plan Parcial de Desarrollo Urbano del Centro Sur de Querétaro (Sombra de Arteaga, 17 de noviembre de 1994), que plantea crear el centro de servicios que la ciudad demanda para descongestionar el Centro Histórico de las actividades que ya no pueden estar en él y para apoyar la creación de una estructura urbana más eficaz con respecto a las actividades que se realizan en la mancha urbana. Se pretende mezclar así una intensidad de usos de suelo y formar un solo conjunto coherente.

En el periodo de gobierno municipal 1997-2000 y por primera vez a cargo del municipio, se elaboraron los Planes Parciales de Desarrollo Urbano de las siete Delegaciones Municipales que componen el Municipio de Querétaro. Esta actividad se realizó a través de la Secretaría de Desarrollo Urbano y Obras Públicas Municipales y el apoyo técnico de consultores locales. Así, se presentó el Plan Parcial de Desarrollo Urbano de la Delegación Josefa Vergara y Hernández (Sombra de Arteaga, 24 de julio de 1997), exponiendo las políticas de conservación y mejoramiento de infraestructura, especialmente en barrios populares; así como de crecimiento orientadas a la atención de requerimientos de suelo necesarios para la expansión urbana resultante de incrementos demográficos. En esta delegación se ubica el Centro Sur y en él, al Centro Cívico.

Finalmente, se presenta el Plan Municipal de Desarrollo 2000-2003 (Sombra de Arteaga, 02 de enero de 2001), con tres líneas estratégicas: la participación ciudadana, para lograr una gestión efectiva y de bienestar social sustentada en la acción conjunta con la sociedad; la planificación de la ciudad, para definir y fortalecer la identidad de la ciudad con proyectos de largo plazo y acciones que mejoren la calidad de vida de la población y el equilibrio ecológico; y, el rediseño de la función gubernamental, para crear un modelo de gobierno que de manera efectiva y medible de respuestas a las demandas de la ciudadanía y optimice el uso de recursos. En lo referente a la estrategia de planificar la ciudad, se planteó, entre otros proyectos, la construcción de un Centro Cívico Municipal que de atención integral a la población y que, en concordancia con la estrategia de rediseño del gobierno municipal; albergue la eficiencia, calidad y calidez del servicio público resultado de un estudio del desarrollo organizacional del municipio. Es decir, el Centro Cívico fue concebido como un símbolo 
de la nueva cultura en el servicio público de Querétaro y que a la vez libera del Centro Histórico las actividades del gobierno municipal. Se concibió también un ahorro significativo en rentas de oficinas y traslados entre dependencias y estacionamientos; así como la mejora en el desarrollo del servidor público y en la atención a la ciudadanía a través de procesos sistematizados de trabajo; una arquitectura tecnológica y de comunicaciones; y una capacitación y desarrollo constante (Ver Fig. 03).
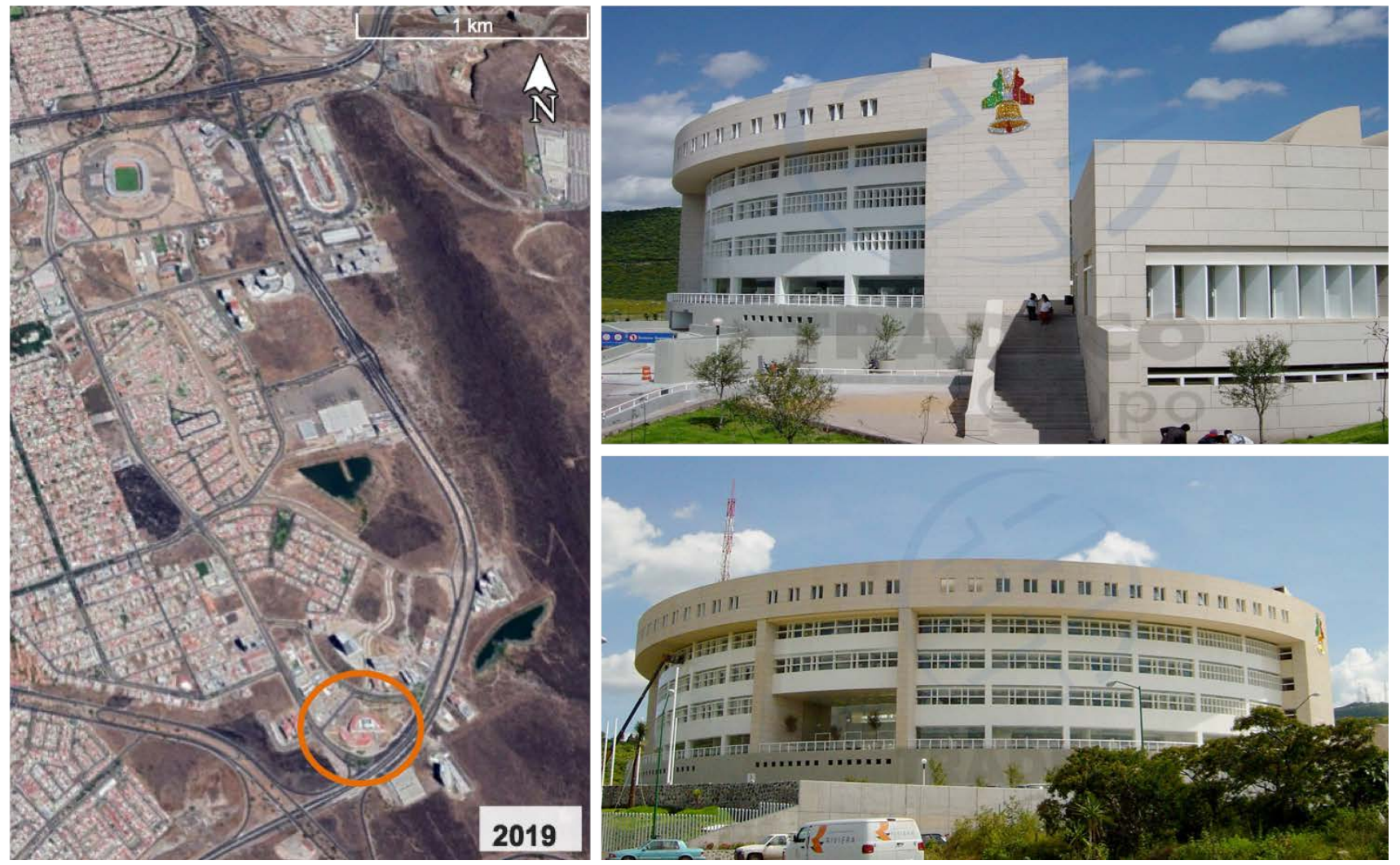

Fig. 03 Centro Sur (izquierda) y Centro Cívico (derecha) de la ciudad de Querétaro. Fuente: Google Earth y Tradeco.com.

\section{A manera de cierre}

Como se ha expuesto, la concepción del Centro Cívico de Querétaro realizada por la planificación estatal no ha contemplado una de las características esenciales en la producción de este tipo de nuevas centralidades: el espacio público, en la acepción teórica aquí expuesta. Se ha limitado más bien, en el marco de la modernización capitalista de las ciudades (Pradilla, 2010), a reproducir los mismos instrumentos utilizados por el urbanismo racionalista del siglo pasado. Con el pretexto de gobernar de mejor forma a las ciudades, es decir planificarlas y gestionarlas en la época contemporánea, se priorizan razones económicas, ya que en la globalización la competitividad económica es un elemento clave, por sobre razones sociales, que pretenden mitigar el problema de la segregación y fomentar la cohesión social. Es decir, se atienden razones políticas, que no solo consideran a estos centros cívicos como unidades sociales que deben estar representadas por una unidad política, sino que los tratan como áreas que tienen una responsabilidad política: son controladas por sus habitantes y sus representantes electos a través de la creación de estructuras institucionales; aunque los objetos urbano-arquitectónicos sea ubicados en la periferia. 


\section{BIBLIOGRAFÍA}

CARRIÓN, F. (2016). El espacio público es una relación, no un espacio. En P. RAMíREZ KURI (Coord.), La reinvención del espacio público en la ciudad fragmentada (13-47). México: UNAM, IIS. - (2017): Comentarios al proyecto de investigación Hábitat y centralidad. En R. COULOMB y V. DELGADILLO (Coords.), Habitar la centralidad urbana (39-51). México: UAM.

DE MATTOS, C. (2010). Globalización y metamorfosis urbana en América Latina. Quito: OLACCHI-MDMQ.

DELGADILLO, V. (2011). Patrimonio histórico y tugurios: las políticas habitacionales y de recuperación de los centros históricos de Buenos Aires, Ciudad de México y Quito. México: UACM. - (2014): La política del espacio público y del patrimonio urbano en la Ciudad de México: discurso progresista, negocios inmobiliarios y buen comportamiento social. Barcelona: XIII Coloquio Internacional de Geo crítica, Universidad de Barcelona. (2017): Conflictos en áreas centrales de conservación patrimonial en la Ciudad de México. En R. COULOMB y V. DELGADILLO (Coords.), Habitar la centralidad urbana (89-115). México: UAM.

DELGADO, M. (2011). El espacio público como ideología. Madrid: Los libros de la catarata.

DUERING, E. (2015). Territorios difusos, murallas reales. Una búsqueda de la raíz de la segregación urbana: Centro Sur de la ciudad de Querétaro. México: Plaza y Valdés Editores.

DUHAU, E. y GIGLIA A. (2004): Espacio público y nuevas centralidades. Dimensión local y urbanidad en las colonias populares de la Ciudad de México. México: Papeles de Población, vol. 10, núm. 41.- (2008): Las reglas del desorden: Habitar la metrópoli. México: Siglo XXI/UAM-A. - (2016): Metrópoli, espacio público y consumo. México: FCE.

GARCÍA, C. (2016). Teorías e historia de la ciudad contemporánea. Barcelona: Gustavo Gili.

HERCE, M.I (2013). El negocio del territorio. Evolución y perspectivas de la ciudad moderna. Madrid: Alianza Editorial.

LEFEBVRE, H. ([1974] 2013). La producción del espacio. Madrid: Capitán Swing.

LUNGO, M. (2005). Globalización, grandes proyectos y privatización de la gestión urbana. Chile: Revista Urbano, julio, año/vol. 8, número 011.

PRADILLA, E. (2010). Mundialización neoliberal, cambios urbanos y políticas estatales en América Latina. Sao Paulo: Cadernos Métropole, Núm. $242^{\circ}$ semestre.

RABOTNIKOF, N. (2005). En busca de un lugar común. El espacio público en la teoría política contemporánea. México: Instituto de Investigaciones Filosóficas UNAM.

SOMBRA DE ARTEAGA (21 de octubre de 1976, 27 de noviembre de 1980, 13 de enero de 1983, 19 de septiembre de 1991, 05 de mayo de 1994, 17 de noviembre de 1994, 24 de julio de 1997, 10 de abril de 1998, 02 de enero de 2001). Diario Oficial del Estado de Querétaro: Archivo Histórico del Estado de Querétaro. 